\title{
Preliminary study on the design of a training status indicator for eventing horses
}

\author{
Izabela Wilk, Iwona Janczarek and Karina Brzozowska \\ Department of Horse Breeding and Use, Faculty of Biology, Animal Sciences and Bioeconomy, University of Life Sciences in Lublin, Poland
}

\begin{abstract}
Summary: The effect of training is the continual improvement of a horse's performance and heart rate is one of the most important indicators in that process. The study proves the hypothesis that a heart rate (HR) analysis during the most important moments of an exercise unit can be useful in everyday training with horses taking part in eventing competitions which require a particularly high training workload from the rider/horse pair. The aim of this paper was to develop a preliminary version of a simple indicator to evaluate the training status of horses prepared for eventing competitions. The research included 16 horses competing in this discipline. It was carried out during a standard exercise unit, at a continuous canter at $450 \mathrm{~m} / \mathrm{min}$ combined with jumps over cross-country obstacles as the main elements. The HR of horses was measured using telemetry devices. An exercise unit was divided into 25 elements. HR readings were taken during subsequent exercise elements. For the design of the training level indicator, exercise elements demonstrating the highest HR progress during the warm-up, canter and jump phases and the greatest HR decrease during recovery in the trot and the walk phases were selected. To design the indicator the following elements were selected: warm-up: 11-15 minutes of trotting and 16-20 minutes of trotting; canter: 4-5 minutes of cantering and jumps 2 and 3; recovery: 2-3 minutes of trotting and 2-3 minutes of walking. Research in this area should be continued and at the moment, this can be considered as a pilot study.
\end{abstract}

Keywords: horse, training, eventing, heart rate, status, indicator

Citation: Wilk I., Janczarek I., Brzozowska K. (2017) Preliminary study on the design of a training status indicator for eventing horses. Pferdeheilkunde 33, 466-471; DOI 10.21836/PEM20170507

Correspondence: Iwona Janczarek, Department of Horse Breeding and Use, University of Life Sciences in Lublin, Akademicka 13, 20950 Lublin, Poland; e-mail: iwona.janczarek@up.lublin.pl

\section{Introduction}

The participation of horses in sport disciplines is one of the key elements in the evaluation and control of the usefulness of horses (Koenen et al. 2004). Since the effect of training is the continual improvement of a horse's performance abilities (von Borstel and Glißman 2014), it can be stated that the need to evaluate and control training with modern methods is unquestionable (Janczarek et al., 2010). There are currently many methods for assessing the level of training horses (Gant et al. 2015, Bergero et al. 2005). Blood tests, lactic acid, oxygen consumption $\left(\mathrm{VO}_{2}\right)$, ventilatory variables (respiratory frequency) in the field or by using a treadmill (Valle et al. 2013, Kędzierski et al. 2009, Hinchcliff et al. 2008) are commonly used. However, such methods are often invasive or require specialized equipment (Dos Santos et al. 2015, McDonough et al. 2002). The assessment of heart rate is non-invasive and easy to carry out. This parameter is significantly correlated with morphological and biochemical blood parameters (Podolak et al. 2004). Resting and exercise HRs are considered to be efficient indicators of the training level of racing and sport horses (Janczarek et al. 2010, Aerts et al. 2008, Young 1999). Evaluation is based on representative elements of training or the course of the entire training unit. According to Janczarek (2003), a systematic heart rate analysis only at rest can also be useful. However, studies conducted in recent years indicate that relying only on averaged $H R$ values in many cases is not precise enough and unsatisfactory for a comparative evaluation of individual horses (Janczarek et al. 2013, Kinnunen et al. 2006). Consequently, increasingly more often indicators of a horse's training status are being developed, which allow for a more comprehensive evaluation of the physiological condition of horses based on HR (Kapro et al. 2001). It is also becoming popular to monitor a horse's condition on the basis of several HR values at the same time (Vermeulen and Evans 2006) and an analysis of not only HR parameters, but also HRV, i.e. heart rate variability (von Borell et al., 2007). However, the application of the latter is most often found in studies focusing on an evaluation of the emotional activity of horses (Stachurska et al. 2015). It can be hypothesized that an analysis based only on HR, but conducted during the most important moments of an exercise unit can be useful in everyday training work with horses taking part in an equestrian discipline which requires a particular training load from the rider/horse pair (Serrano et al. 2002). For this reason, the aim of our paper was to develop a preliminary version of a simple indicator to evaluate the training status of horses prepared for eventing competitions.

\section{Materials and methods}

The study involved 16 Polish warmblood gildings aged from 7 to 10 years, participating in eventing competitions. During the study, the horses remained in one training centre where they were prepared for their first start in an EFI one star event of that season. In the previous racing season, each of the horses had participated at least once in events at this level. Horses were brought to the training center 30 days before the study was conducted. They came from three different centers located a maximum of 20-30 km from each other. All horses were trained by the same trainer according to the same training cycle and were stabled in a box type stable (box dimensions: $3 \times 3 \mathrm{~m}$ ). The floor of the box was padded with straw which horses could eat at will. Horses were fed three times a 
day: six $\mathrm{kg}$ of hay and seven $\mathrm{kg}$ of solid feed in three doses ( $5 \mathrm{~kg}$ of oats and $2 \mathrm{~kg}$ high-energy pellets for sport horses).

Horse were ridden on a grass track on which obstacles were set. Track quality was measured using Ground Penetrating Radar. Riders were of the same sports class. Each of the riders had been riding the same horse for at least a year. One rider rode between three to five horses.

The research was carried out during the exercise unit, with the main element being a continuous canter at $450 \mathrm{~m} / \mathrm{s}$ combined with jumps over cross-country obstacles. The scheme of the exercise unit was as follows: warm-up -10 min of walking $160-170 \mathrm{~m} / \mathrm{min}$ (the first walk), $20 \mathrm{~min}$ of trotting $210-220 \mathrm{~m} / \mathrm{min}, 5 \mathrm{~min}$ of walking $160-170 \mathrm{~m} / \mathrm{min}$ (second walk); next -5 min of cantering with jumps; rest (recovery) 5 min of trotting and $15 \mathrm{~min}$ of walking. After each minute of cantering, the horses made one jump (Tab. 1).

Table 1 Type and dimensions of subsequent obstacles negotiated by horses.

\begin{tabular}{cccc}
\hline Sequence of obstacles & Type & Height $(\mathrm{cm})$ & Width $(\mathrm{cm})$ \\
\hline 1 & vertical & 100 & - \\
2 & oxser & 90 & 100 \\
3 & vertical & 100 & - \\
4 & oxser & 90 & 110 \\
5 & oxser & 100 & 120 \\
\hline
\end{tabular}

A commercial HR monitor was attached to the thoraxes of the horses (Polar type S810) according to the instructions of the manufacturer (Polar Electro Oy Kempele, Finland). The HR was recorded at $5 \mathrm{~s}$ intervals. Data from the memory of the receiver were then transferred to a computer and analysed in special software (Polar Precision Performance 2.0). The speed was measured using Polar GPS devices which were placed on the rider's hand. The following HR recordings were made:

- Resting (recorded in the stable before starting the research for $5 \mathrm{~min})$.

- Exercise unit (recorded from the moment of starting the first walk until the end of the canter).

- Recovery (recorded for 30 min from the moment of ending the canter).

Synchronisation of the manual stopwatch (SEIKO S 141) with the monitor stopwatch facilitated a detailed description of HR values during the performance of subsequent elements of the exercise for each horse.

The following readings of mean HR of the horses were taken: resting HR over the entire measurement; exercise HR over the entire exercise, and HR measured for the following elements:
- Warm-up - HR over the entire warm-up phase, HR during the first walk, HR during the first $5 \mathrm{~min}$ of trotting, $H R$ in minutes 6 to 10 of trotting, HR in minutes 11 to 15 of trotting, HR in minutes 16 to 20 of trotting, HR during the second walk.

- Canter - pulse over the entire cantering phase and HR in the first minute of cantering, HR in the second minute of cantering, $H R$ in the third minute of cantering, $H R$ in the fourth minute of cantering, $H R$ in the fifth minute of cantering, HR after the first jump, HR after the second jump, HR after the third jump, HR after the fourth jump, HR after the fifth jump (for all jumps, the time of measurement was 15s).

- Recovery - HR over the entire resting period after the canter and $H R$ over the entire period of trotting, HR in the first minute of trotting, $H R$ in the second minute of trotting, $H R$ in the third minute of trotting, $H R$ in the fourth minute of trotting, HR in the fifth minute of trotting, HR over the entire period of the third walk, HR in the first minute of the third walk, HR in the second minute of the third walk, HR in the third minute of the third walk.

In order to design a training status indicator, exercise elements demonstrating the highest $H R$ progress during the warm-up, canter, jumps and the greatest HR regress during the recovery phase in trotting and walking were selected.

The elements chosen in this way were considered to be the most characteristic (crucial) for the type of eventing horse training analysed in this study (Amory et al. 1993). They became components of the designed indicator with the underlying assumption that the higher the exercise level of the horses, the lower the HR progress during the warm-up and canter and the regress was greater during the resting and recovery phases.

An analysis of variables was conducted using PQStat software (Więckowska 2013). Tukey's test was used to determine the significance of differences between means and percentage reports were prepared and standard deviation has been calculated. The difference between percentages was determined using Parker test (Parker 1978).

\section{Results}

Resting HR was $29.3 \mathrm{bpm}(\mathrm{SD}=3.22)$. The mean exercise $H R$ was $124.6 \mathrm{bpm}(\mathrm{SD}=11.98)$.

The mean HR during the warm-up phase was $78.4 \mathrm{bpm}$, with $62.6 \mathrm{bpm}$ during the first walk, $65.4 \mathrm{bpm}$ during the second walk, and $88.7 \mathrm{bpm}$ over the entire trotting phase (Tab. 2). In subsequent time intervals of trotting lasting 20 min., a significant increase in the discussed parameter was recorded.

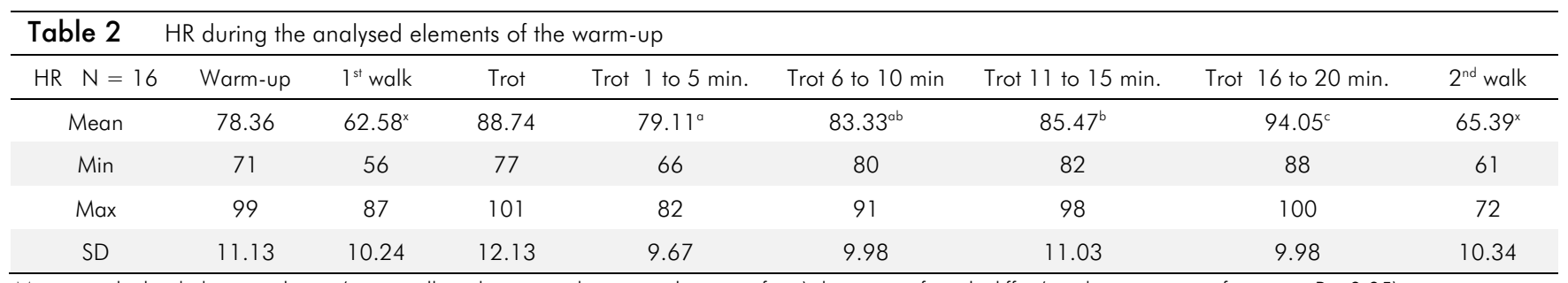

Means marked with the same letters ( $\mathrm{x}$ - in walk; $a, b, c-$ in subsequent elements of trot) do not significantly differ (in other cases. significance at $\mathrm{P} \leq 0.05$ ). 


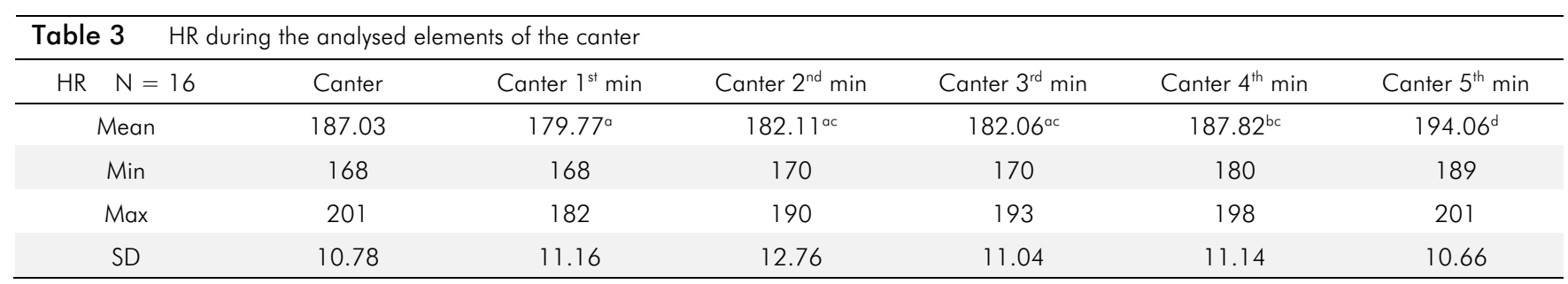

Means marked with the same letters do not significantly differ (in other cases. significance at $P \leq 0.05$ ).

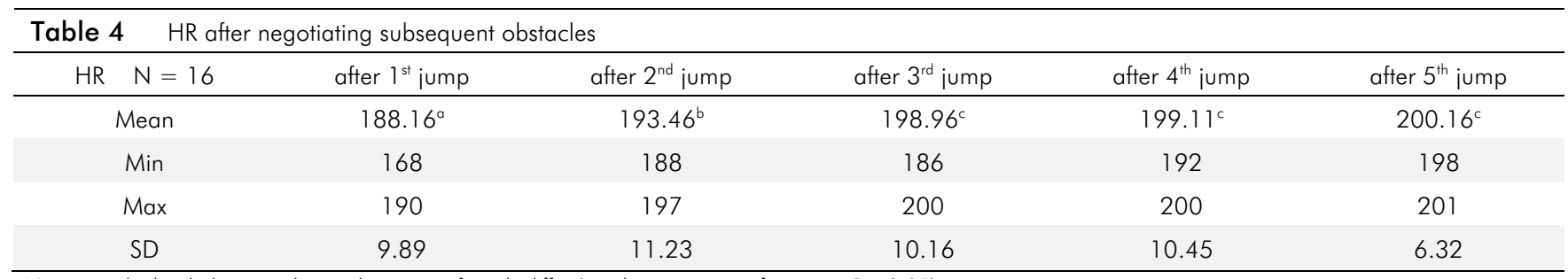

Means marked with the same letters do not significantly differ (in other cases. significance at $\mathrm{P} \leq 0.05$ ).

\begin{tabular}{|c|c|c|c|c|c|c|}
\hline $\mathrm{HR} N=16$ & Trot & Trot $1^{\text {st }} \min$ & Trot $2^{\text {nd }} \min$ & Trot $3^{\text {rd }} \min$ & Trot $4^{\text {th }}$ min & Trot $5^{\text {th }} \min$ \\
\hline Mean & 126.11 & $167.45 a$ & $159.45 b$ & $130.08 c$ & $122.21 d$ & $112.17 \mathrm{e}$ \\
\hline Min & 102 & 121 & 117 & 113 & 109 & 102 \\
\hline Max & 178 & 178 & 167 & 143 & 129 & 116 \\
\hline SD & 10.23 & 12.18 & 10.22 & 11.78 & 9.34 & 9.04 \\
\hline
\end{tabular}

Means marked with the same letters do not significantly differ (in other cases. significance at $\mathrm{P} \leq 0.05$ ).

Table 6 HR during the analysed elements of walking in the recovery phase

\begin{tabular}{ccccc}
\hline $\mathrm{HR}$ & Walk & Walk $1^{\text {st }}$ min & Walk $2^{\text {nd }}$ min & Walk $3^{\text {rd }}$ min \\
\hline Mean & 82.66 & $78.34^{\mathrm{a}}$ & $76.22^{\mathrm{a}}$ & $71.13^{\mathrm{b}}$ \\
Min & 67 & 71 & 69 & 67 \\
Max & 100 & 100 & 88 & 82 \\
$\mathrm{SD}$ & 11.16 & 13.76 & 10.07 & 8.11 \\
\hline
\end{tabular}

Means marked with the same letters do not significantly differ

(in other cases, significance at $\mathrm{P} \leq 0.05$ ).

The mean HR during the canter was $187 \mathrm{bpm}$ (Tab. 3). The discussed parameter during consecutive minutes increased successively, with a final value exceeding $194 \mathrm{bpm}$. Similar values occurred only in the three first minutes of the effort. The mean HR after negotiating subsequent obstacles during the canter ranged from $188.6 \mathrm{bpm}$ during the first jump to 200.2 bpm during the last jump (Tab. 4). Values that did not significantly differ were observed for jumps 3, 4 and 5 . The mean HR during trotting in the recovery phase was $126.1 \mathrm{bpm}$ (Tab. 5). A significant regress of HR measured after subsequent minutes of trotting was observed. The mean HR during the recovery walk was $82.7 \mathrm{bpm}$ (Tab. 6). HR after the third minute of walking was significantly higher than the $H R$ after the first two minutes.

During the warm-up, a constant increase of HR of the examined horses was observed (Tab. 7). During the walk, it was almost $5 \%$. In the trotting phase, the highest progress was recorded in the last five minutes. On the other hand, a clearly lower increase was seen for the first $15 \mathrm{~min}$. of the analysed type of gait.
During the trot, there was a successive increase of HR. During the first four minutes, it ranged from $0.5 \%$ to $2.0 \%$. However, a much more visible regress was observed after the fifth minute of the effort in relation to HR after the fourth minute.

HR changes during subsequent jumps of the examined horses were insignificant. They were most visible after the second jump in comparison to HR after the first jump and after the third jump in comparison to HR after the second jump.

During the recovery phase, a decrease in HR was observed in subsequent minutes of its duration. The greatest HR regress occurred after the third minute of trotting in comparison to HR after the second minute. For walking, there was a $3 \%$ decrease after the second minute and $7 \%$ after the third minute.

According to our results, the following elements of an exercise unit were used to design the Training Status Indicator for Eventing Horses $\left(\mathrm{TSI}_{\mathrm{EH}}\right)$ :

- 1 warm-up: 11-15 minutes of trotting and 16-20 minutes of trotting.

- 2 canter: 4-5 minutes of cantering and 3-4 jumps.

- 3 recovery: 2-3 minutes of trotting and 2-3 minutes of walking.

Based on the obtained results the following formula for the $\mathrm{TSI}_{\mathrm{EH}}$ has been proposed:

$$
\mathrm{TSI}_{\mathrm{EH}}=\mathrm{X} 1+\mathrm{X} 2+\mathrm{X} 3-(\mathrm{X} 4+\mathrm{X} 5)
$$

$X 1-X 5$ express as percentages, the difference in the HR value for the following pairs of exercise elements: $X 1$ - warm-up: 


\begin{tabular}{|c|c|c|c|c|c|c|}
\hline \multirow{2}{*}{$\begin{array}{l}\text { HR increase in (\%) } \\
\text { Warm-up }\end{array}$} & \multicolumn{6}{|c|}{ Exercise elements } \\
\hline & $\begin{array}{l}2^{\text {nd }} \text { walk } \\
\text { relative to } 1^{\text {st }} \text { walk }\end{array}$ & $\begin{array}{l}\text { Trot from } 6 \text { to } 10 \mathrm{~min} \\
\text { relative to trot } \\
\text { from } 1 \text { to } 5 \mathrm{~min}\end{array}$ & $\begin{array}{c}\text { Trot from } 11 \text { to } 15 \\
\text { min relative to trot from } \\
6 \text { to } 10 \mathrm{~min}\end{array}$ & $\begin{array}{l}\text { Trot from } 16 \text { to } 20 \\
\text { min relative to trot } \\
\text { from } 11 \text { to } 15 \mathrm{~min}\end{array}$ & & \\
\hline Mean & $4.5 a$ & $5.5 a$ & $3 a$ & $10 b$ & & \\
\hline Min & 9 & 21 & 2.5 & 7.5 & & \\
\hline Max & 17 & 11 & 8 & 2 & & \\
\hline Canter & $\begin{array}{l}\text { Canter } 2^{\text {nd }} \min \\
\text { relative to canter } \\
1^{\text {st }} \min \end{array}$ & $\begin{array}{l}\text { Canter } 3^{\text {rd }} \min \\
\text { relative to canter } 2^{\text {nd }} \text { min }\end{array}$ & $\begin{array}{l}\text { Canter } 4^{\text {th }} \mathrm{min} \\
\text { relative to canter } 3^{\text {rd }} \\
\text { min }\end{array}$ & $\begin{array}{l}\text { Canter } 5^{\text {th }} \text { min } \\
\text { relative to canter } 4^{\text {th }} \\
\text { min }\end{array}$ & & \\
\hline Mean & $1.5 a$ & $0.5 a$ & $2 a$ & $4 b$ & & \\
\hline Min & 1 & 0 & 0.5 & 1.5 & & \\
\hline Max & 4.5 & 1.5 & 3 & 7.5 & & \\
\hline After obstacles & $\begin{array}{l}\text { after } 2^{\text {nd }} \text { jump } \\
\text { relative to after } 1^{\text {st }} \\
\text { jump }\end{array}$ & $\begin{array}{l}\text { after } 3^{\text {rd }} \text { jump } \\
\text { relative to after } 2^{\text {nd }} \text { jump }\end{array}$ & $\begin{array}{c}\text { after } 4^{\text {th }} \text { jump relative to } \\
\text { after } 3^{\text {rd }} \text { jump }\end{array}$ & $\begin{array}{l}\text { after } 5^{\text {th }} \text { jump relative } \\
\text { to after } 4^{\text {th }} \text { jump }\end{array}$ & & \\
\hline Mean & $3 a$ & $3 a$ & $\mathrm{Ob}$ & $0.5 b$ & & \\
\hline Min & 1 & -1 & 1 & 0.5 & & \\
\hline Max & 4 & 1.5 & 3 & 2.5 & & \\
\hline Recovery & $\begin{array}{l}\text { after } 2^{\text {nd }} \min \text { trot } \\
\text { relative after } 1^{\text {st }} \\
\text { min trot }\end{array}$ & $\begin{array}{l}\text { after } 3^{\text {rd }} \text { min trot relative } \\
\text { after } 2^{\text {nd }} \text { min trot }\end{array}$ & $\begin{array}{c}\text { after } 4^{\text {th }} \mathrm{min} \text { trot relative } \\
\text { after } 3^{\text {rd }} \mathrm{min} \text { trot }\end{array}$ & $\begin{array}{l}\text { after } 5^{\text {th }} \text { min trot } \\
\text { relative after } 4^{\text {th }} \text { min } \\
\text { trot }\end{array}$ & $\begin{array}{l}\text { after } 2^{\text {nd }} \min \\
\text { walk relative after } \\
1^{\text {st }} \text { min walk }\end{array}$ & $\begin{array}{l}\text { after } 3^{\text {rd }} \text { min walk } \\
\text { relative after } 2^{\text {nd }} \\
\text { min walk }\end{array}$ \\
\hline Mean & $-5 a$ & $-18.5 b$ & $-6 a$ & $-8 a$ & $-3 a$ & $-7 a$ \\
\hline Min & -3.5 & -3.5 & -3.5 & -6.5 & -2 & -2 \\
\hline Max & -7 & -21.5 & -10 & -10 & -12 & -10 \\
\hline
\end{tabular}

Means analysed in subsequent elements of exercise (warm-up, canter, after obstacles, recovery) marked with the same letters do not significantly differ (in other cases, significance at $\mathrm{P} \leq 0.05$ ).

trotting - the period between minute 16 and minute 20 in comparison with the period between minute 11 to minute 15, X2 - proper effort: canter in minute 5 in comparison with canter in minute $4, \mathrm{X} 3$ - proper effort: third jump in comparison with the second jump, $X 4$ - recovery, trot in the third minute in comparison with trot in the second minute, X5 - recovery: walk in the third minute in comparison with walk in the second minute.

\section{Discussion}

In this study we found that mean values of resting $H R$ and $H R$ over the entire period of effort are comparable to those reported by other authors examining eventing horses during a similar exercise entity (Marlin and Nankervis 2013, Serrano et al. 2002, Amory et al. 1993). Therefore, it can be assumed that the examined group of horses is typical, i.e. within the HR referential ranges for this type of effort (Muñoz et al. 1999). On the other hand, analysing individual stages of exercise, Janczarek (2003) claimed that the warm-up is a valuable stage to be used to evaluate a competitive horse's performance capacity. It is interesting that a detailed analysis of $\mathrm{HR}$ before beginning the proper effort, i.e. during the warm-up phase, shows significant differences between HR in subsequent minutes of the trot. Vermeulen and Evans (2006) reported that the capacity of a horse's body is high when no significant HR fluctuations are observed during the walk and after the warm-up trot, as well as in subsequent minutes of the trot. This may indicate that at the moment of observation, the examined horses were not yet in their peak form. Another issue that should be noted is related to the quite high values of a standard deviation obtained during the HR analysis for the warm-up which could prove the differences of the physical form of the examined horses as well as emphasize the possibility of using this stage of the exercise unit for evaluation of individual horses. A similar opinion is shared by Janczarek (2003).

Interesting results were also obtained in HR analyses of specific minutes of the canter. It is noteworthy that there is a similar level of the parameter, but only during the first three minutes of the effort. It can be assumed that the last two minutes of cantering proved too exhausting for the horses examined in this study. Harkins et al. (1993) found that the HR of a welltrained horse during the canter at a constant speed should not increase. The progress of the above-mentioned heart rate parameter is only acceptable in the case of exercise with a varied pace or during cantering at a rate of over $80 \%$ of the maximum physical capacity. The response of the cardiovascular system indicates adaptation to effort (Young 1999).

The situation was slightly different when horses made several jumps. A significant increase of HR took place while clearing the first three obstacles. This may result from emotions experienced by horses when the jump phase starts (Janczarek et al. 2010) or from a slightly greater effort after a several- 
minute canter compared to jumps made during the canter. However, it is difficult to compare the results obtained in this case to the research of others, since a comparative analysis of the effort made by horses negotiating obstacles and the effort related only to cantering has not yet been carried out.On the other hand, a statistically significant decrease in the HR of horses during the recovery phase indicated that horses coped with the effort they were subjected to during exercise. Hamlin et al. (2002) found that a heart rate frequency maintained at a similar level during rest could reflect fatigue of the body due to effort on a given day, overtraining or health problems. The results of this study did not clearly find any anomalies of this type.

According to Aerts et al. (2008), analysis of the training condition of a horse based on averaged HR values can sometimes lack precision. In such a case, the application of HR variables or determination of differences in the heart rate levels that take into account various exercise elements can be useful. A good training status is shown by the lowest possible HR progress during movement at the same speed and the greatest possible regress of the examined parameter during rest. This study demonstrated that during the warm-up, the most visible increase of HR was recorded in the last minutes of the trot. A similar situation also occurred in subsequent minutes of the canter. Marlin and Nankervis (2013) found that such a response of the body to the warm-up or canter at low speed may indicate incorrect adjustment of the training cycle. At the same time, a much less pronounced increase in HR during jumps emphasizes the need to carry out further research on the effect of negotiating obstacles during the training canter of eventing horses to enhance the exercise response.

It was assumed that for the warm-up and cantering phases a lower HR increase in subsequent minutes of effort of the same intensity demonstrated a higher training status of a given horse and, for the recovery phase, a higher training status was reflected by a greater HR decrease in subsequent minutes of the recovery. This assumption was based on the results of studies published by Janczarek et al. (2010). It was concluded that more advanced training of a horse would result in a lower value of the proposed indicator. With this assumption, and on the basis of published studies (Serrano et al. 2002) concerning the HR level at analogous training stages, the following formula for the proposed indicator has been designed.

\section{Conclusion}

Based on the results of this study a simple indicator was designed which can be used to assess the training of horses which took part in eventing. However, the study should be continued on a larger number of horses, and prepared for various ranks of eventing competitions, etc. At the moment, the research can be considered as a pilot study.

\section{Animal welfare statement}

Animal care and experimental procedures were in accordance with the European Committee Regulations on Protection of Experimental Animals and were approved by the Local Ethic Review Committee for Animal Experiments (ref. no 56/2015).

\section{Conflict of interest statement}

The authors certify that they have no affiliations with or involvement in any organization or entity with any financial interest, or non-financial interest in the subject matter or materials discussed in this manuscript.

\section{References}

Aerts J., Gebruers F., Van Camp E., Berckmans D. (2008) Controlling horse heart rate as a basis for training improvement. Comp. Electron. Agricult. 64, 78-84

Amory H., Art T., Linden A., Desmecht D., Buchet M., Lekeux P. (1993) Physiological response to the cross-country phase in eventing horses. J. Equine Vet. Sci. 13, 646-650

Bergero D., Assenza A., Caola G. (2005) Contribution to our knowledge of the physiology and metabolism of endurance horses. Livestock Prod. Sci. 92, 167-176

Dos Santos V. P., Gonzalez F. D., da Costa Castro Jr. J. F., Castro T. F. (2015) Hemato-biochemical response to exercise with ergometric treadmill, mount training and competition in jumping horses. Arch. Vet. Sci. 20, 1-8

Gent T. C., Schwarz A., Hatz L. A., Gozalo-Marcilla M., Schauvliege S., Regula F. G. (2015) Evaluation of accuracy of invasive and noninvasive blood pressure monitoring in relation to carotid artery pressure in anaesthetised ponies. Pferdeheilkunde 31, 33-38

Hamlin M. J., Shearman J. P., Hopkins W. G. (2002) Changes in physiological parameters in overtrained Standardbred racehorses. Equine Vet. J. 34, 383-388

Harkins J.D., Beadle R.E., Kamerling S. G. (1993) The correlation of running ability and physiological variables in Thoroughbred racehorses. Equine Vet. J. 25, 53-60

Hinchcliff K. W., Kaneps A. J., Geor R. J. (2008) Equine exercise physiology: The science of exercise in the athletic horse. Elsevier Health Sciences

Janczarek I. (2003) Parametry oceny zaawansowania treningowego koni wy cigowych. Roczniki Naukowe Zootechniki, Suplement, z. 18, 205-210 (in Polish)

Janczarek I., Bocian K., Wilk I. (2010) Utilization of cardic work indices for estimating free jumps of young half-bred stallions. Annales UMCS, XXVIII, Sectio EE, 8-16

Janczarek I., Stachurska A., Kędzierski W., Wilk I. (2013) Responses of horses of various breeds to a sympathetic training method. J. Equine Vet. Sci. 33, 794-801

Kapro M., Janczarek I., Pluta M., Bocian K., Suska A. (2001). Wspolzaleznosc miedzy wybranymi wskaznikami zaawansowania treningowego ogierow polkrwi w ramach testu 100 dni oraz koncowymi wynikami prob dzielnosci. Roczniki Naukowe Zootechniki. Suplement 14, 109-117. (in Polish)

Kedzierski W., Bergero D., Assenza A. (2009). Trends of hematologi$\mathrm{cal}$ and biochemical values in the blood of young race horses during standardized field exercise tests. Acta Vet. 59, 457-466

Kinnunen S., Laukkanen R., Haldi J., Hanninen O., Atalay M. (2006) Heart rate variability in trotters during different training periods. Equine Vet. J. Suppl 36, 214-217

Koenen E. P. C., Aldridge L. I., Philipsson J. (2004) An overview of breeding objectives for warmblood sport horses. Livestock Production Sci. 88, 77-84

Marlin D., Nankervis K. J. (2013) Equine exercise physiology. Wiley McDonough, P., Kindig, C. A., Ramsel, C., Poole, D. C., Erickson, H. $H$. (2002) The effect of treadmill incline on maximal oxygen uptake, gas exchange and the metabolic response to exercise in the horse. Experimental Physiology 87, 499-506

Muñoz A., Riber C., Santisteban R., Rubio M. D., Agüera E. I. (1999) Cardiovascular and metabolic adaptations in horses competing in cross-country events. J. Vet. Med. Sci. 61, 13-20

Parker R. E. (1978) Wprowadzenie do statystyki dla biologów [Introduction to the statistics for biologists]. PWN Warszawa. 133-136 (in Polish) 
Podolak M., Kedzierski W., Janczarek I. (2004) Intense training of Arabian horses and its effect on thelevel of selected biochemical indices in their blood and heart rate. Med Wet. 4, 403-406

Serrano M. G., Evans D. L., Hodgson,J. L. (2002) Heart rate and blood lactate responses during exercise in preparation for eventing competition. Equine Vet. J. 34, 135-139

Stachurska A., Janczarek I., Wilk I., Kędzierski W. (2015) Does Music Influence Emotional State in Race Horses? J. Equine Vet. Sci. 35, 650-656

Vermeulen A. D., Evans D. L. (2006) Measurements of fitness in thoroughbred racehorses using field studies of heart rate and velocity with a global positioning system. Equine Vet. J. Suppl. 36, 113-1 17 von Borell E., Langbein J., Després G., Hansen S., Leterrier C., Marchant-Forde J., Valance D. (2007) Heart rate variability as a measure of autonomic regulation of cardiac activity for assessing stress and welfare in farm animals - a review. Physiol. Behav. 92, 293-316

Valle E., Odore R., Zanatta P. R., Badino P., Girardi C., Nery J., Bergero $D$. (2013) Estimation of the workload in horses during an eventing competition. Comp. Exerc. Physiol. 9, 93-101

von Borstel U. K., Glißman C. (2014) Alternatives to conventional evaluation of rideability in horse performance tests: suitability of rein tension and behavioural parameters. PloS one, 9, e87285

Więckowska B. (2013) Podręcznik użytkownika-PQStat. PQStat Software

Young L. (1999) Cardiac responses to training in 2-year-old Thoroughbreds: an echocardiographic study. Equine Vet. J. Suppl. 30, 195-198 